\title{
Elbasani në regjistrimet osmane të viteve $1431,1468,1530$ dhe 1568
}

Ermal Nurja

Periudha e sundimit osman në trevat shqiptare, në Ballkan, në përgjithësi dhe ajo në Shqipëri, në veçanti, mbetet ende një periudhë, për të cilën dokumentacioni kohor duhet zbardhur në mënyrë që të kuptohen më mirë jo vetëm historia politike, por edhe ajo ekonomike, sociale, demografike brenda së cilës janë të ngërthyer një sërë faktesh që kanë të bëjnë drejtpërdrejt ose tërthorë me zhvillimin e kombit shqiptar.

Dy ishin shenjat e vendosjes së sundimit osman në një trevë, caktimi i një kadiu si përfaqësues dhe zbatues i ligjit osman dhe aplikimi i sistemit të timareve në atë trevë. Shtrirja osmane kryhej së pari në zonat mes luginave dhe zonat fushore, ku rezistenca ishte e dobët për shkak të pozitës gjeografike dhe për faktin se aty gjendeshin dhe tokat bujqësore nga ku mund të mblidhej prodhimi bujqësor për t'u taksuar. Zonat malore nuk ishin në fokusin e shtrirjes së parë osmane, ndërkohë që kalatë dhe grykat e rëndësishme malore për komunikimin rajonal përfshiheshin në interesin e pushtimit në fazën e dytë. Për grykat e rëndësishme të kalimit mes zonave malore (dervenet) osmanët përdornin politikën e faljes së taksave për popullsinë vendase kundrejt shërbimit të tyre për ruajtjen e rendit dhe sigurisë në ato pika.

Meqë dokumentet osmane në Shqipëri janë shkatërruar me kalimin e kohës, Arkivi Osman i Stambollit paraqet rëndësi të dorës së parë për të dhëna historike që kanë të bëjnë me Shqipërinë dhe shqiptarët.

Për shkak të hapësirës së këtij artikulli, do të mjaftohemi duke prezantuar në mënyrë të përmbledhur të dhënat që gjenden në katër regjistra tahrir që ruhen në Arkivin Osman të Stambollit, sidomos të dhënat historike që kanë të bëjnë me historinë e qytetit dhe sanxhakut të Elbasanit. 


\section{Albanon}

Revistë kulturore

Regjistrat ruhen në Arkivin e Stambollit, në tri fonde të ndryshme TT.d 1M: regjistri i Arvanidit (Arvanid defteri); MAD 508: regjistri i detajuar i vilajetit të Dibrës, DFE.TD 367: regjistri i përmbledhur (ixhmal) i Rumelisë; TT.d 477: regjistri i detajuar i sanxhakut të Elbasanit.

Në periudhën klasike të sundimit osman, toka kishte tri statute juridike; mirije kur i takonte shtetit, private (mylk) kur i takonte individit (mylknameja i akordohej personit nga sulltani) dhe vakëf, kur i takonte një objekti fetar apo bamirës. Pjesa dërrmuese e tokave i takonte shtetit, në planin juridik, pra ai (sulltani) kishte të drejtë që t’ia "hiqte doret" të zotit të saj, për arsye të ndryshme, në dallim nga prona private (mylk) së cilës edhe vetë sulltani nuk mund t'ia ndërronte statusin, vetëm në rast shitblerje apo dhurimi nga i zoti. Tokat vakëf, ligjërisht, nuk e ndryshonin statusin e tyre, pasi shitja e pronës vakëf, sipas ligjeve klasike myslimane, ishte e ndaluar.

Të ardhurat e këtyre tokave shpëndaheshin një pjesë drejt thesarit të sulltanit, ndërsa pjesa tjetër për timarlinjtë ose nëpunësit e tjerë të shtetit. I gjithë ky sistem financiar njihej nën emrin timari. Timaret nën 20 '000 akça vazhdonin të mbanin këtë emër, ato që varionin mes 20 mijë dhe 100 mijë akçave quheshin zeamet, ndërsa ato që kalonin 100 mijë akçat quheshin hase. Regjistrat e tahrireve shkruheshin pikërisht për të regjistruar sistemin e timareve brenda një sanxhaku. ${ }^{1}$

\section{Regjistri Arvanid i vitit 1431}

Organizimi administrativ i kësaj periudhe synonte një regjistrim dhe përfshirje të trevave të Shqipërisë së Jugut dhe të Mesme nën emrin sanxhaku Arvanid. Regjistri i Korçës dhe Përmetit i klasifikuar dhe gjetur në një fond tjetër në Arkivin Osman të Kryeministrisë, nuk është gjë tjetër, por një pjesë e regjistrit Arvanid, për të cilin po flasim. Ky është edhe opinioni i historianit turk Halil Inallxhikut, i cili botoi këtë regjistër.

Në regjistrin e vitit 1431 (835 hixhri) të sanxhakut Arvanid, Elbasani si toponomi nuk ekziston. Në këtë periudhë, ajo që më pas do të organizohet nën emrin e kazasë së Elbasanit, përfshihet nën disa ndarje administrative.

Treva e Elbasanit në këtë regjistrim përfshihej si pjesë e vilajetit të Pal Kurtiqit (Pavlo Kurtiq). Fakti që një nëndarje administrative e madhe për këtë kohë

1 Studimi më i mirë i kryer deri më sot në lidhje me regjimin e sistemit të timareve në Shqipëri është vepra e historianit shqiptar Selami Pulaha, Pronësia feudale në tokat shqiptare: shek. XV-XVI, Tirana 1988. 
(vilajet) merrte emrin e një ish zoti shqiptar, tregon se ai duhet të ishte një nga fisnikët e rëndësishëm lokalë që sundonin në hapësirën shqiptare para ardhjes së osmanëve. Për këtë personazh, burimet shqiptare të kohës (Barleti dhe Gjon Muzaka) nuk japin asnjë informacion, ndërkohë që historianët shqiptarë të periudhës moderne shohin te ky person një pasardhës të një principate të rëndësishme që duhet të ketë vepruar në atë trevë që në kohën e sundimit bizantin. ${ }^{1}$ Administrimi i këtij vilajeti i qe lënë të birit të tij, i cili ishte bërë mysliman e më pas jeniçer duke bërë përpara në administratën ushtarake osmane, saqë kishte marrë edhe titullin bej, e quhej Isa bej biri i Pal [Pavlo] Kurtiqit. Vilajeti në fjalë formohej nga disa nahije që ishin ato të Zhilemës (pjesërisht mbulon Tiranën e sotme), Kërraba (Kraplar), pjesë nga vilajeti i Kondo Mihos (vetëm dy fshatra: Bradashesh, Petrash), ${ }^{2}$ nahija e Margjeshit (pjesa lindore e Peqinit), nahija e Pajadhas, pjesë e livasë së Gjonimës (pjesa veriore e trevës së Peqinit), Tomonishta, Luzi dhe Ermeni, nga vilajeti i Balshës. ${ }^{3}$

Treva që mbulonte zonën mes Elbasanit, Beratit dhe Tomorricës (pra treva e Librazhdit dhe e Gramshit) organizohej në vitin 1431 nën emrin vilajeti i Cartalosit. ${ }^{4}$

Qendra e vilajetit të Isa bej Kurtiqit, ishte fshati Bradashesh. Sipas të dhënave që gjenden në regjistrin e Arvanidit, osmanët në këtë fshat kishin ndërtuar edhe një kala që e quanin Jenixhe Kale, që do të thotë Kalaja e Re. ${ }^{5}$ Në këtë kala ishin vendosur një repart ushtarak me në krye një dizdar dhe një kadi.

Timari i Isa bej Kurtiqit përfshinte gjithë vilajetin e Pal Kurtiqit, nga e cila

1 Dhimitër Shuteriqi hedh hipotezën se ai ishte një feudal nga Kërraba, fisit të të cilit i gjehen gjurmët që në shekullin e XI, te një Vasil Kurtikios, përkrahës i perandorit Aleks Komnen, i cili kontriboi në thyerjen dhe fitoren kundër dukës së Durrësit, që kishte ngritur krye ndaj perandorit. (Dhimitër Shuteriqi, Aranitët: Zotërimet, Studime Historike, 1967/1, fq. 70.) Familja e Pal Kurtiqit përveç Isa beut, do të angazhohej me figura të tjera në administratën osmane, me një djalë tjetër të tijin Mustafa beun, i cili kishte një timar në Berat, ndërkohë që bijtë e Isa bej Kurtiqit, Ibrahimi dhe Jusuf më 1455 kishin timar në Trikalla, ndërsa në 1460 lbrahimi e rrit timarin e tij në zeamet me pjesë nga Moreja. Historiani turk Halil Inallxhik ka identifikuar edhe dy personalitete të rëndësishme të kësaj familjeje në oborrin e sulltan Mehmetit të II, Musa bej Kurtiqi dhe Mehmet bej Kurtiqi, me gradën subash. (Halil İnalcık, Timariotes chretienes, Fatih ve İstanbul, 1953, f. 124-126.)

2 Kondo Miho ishte nga dera e bujarve Aranitas, Arvanid defteri, 59, 86.

3 Arvanid defteri, 85-89.

4 Arvanid defteri, 97-102.

5 Sipas Gjerak Karaiskaj, nga kjo kala nuk ka mbërritur asnjë gjurmë; 5000 vjet fortifikime në Shqipëri, Tiranë 1981, f. 202 


\section{AlBanon}

\section{Revistë kulturore}

financa osmane grumbullonte një të ardhur vjetore prej 81'306 akçash, kundrejt të cilave sanxhakbeu i saj, përveç detyrimeve lokale si administratë osmane, duhej të paraqitej çdo herë që ta urdhëronte sulltani, me 14 ushtarë të armatosur për luftë.

Regjistri i Arvanidit jep një listë të mbrojtësve të kalasë së Bradasheshit që janë: Tanrëvermish (dizdari), Shahini, Hamza, Mehmedi, Ajdin Gjegji, Ballabani, Saruxha, Ibrahimi biri i Ballabanit të gjatë, Aliu (vëlla i Ajas Hamza bej), Ajdini, Aliu biri i Karlit (me gjasa një shqiptar i bërë mysliman) ${ }^{1}$; pra në total 10 ushtarë me në krye një dizdar (kastelan kështjelle).

Sipas regjistrit Arvanid një pjesë e trevës së Elbasanit ka qenë nën sundimin osman qysh në kohën e ripërtëritjes së aparatit osman në Ballkan, pas ardhjes në pushtet të sulltan Mehmetit të I (1413-1421). Në tekst ky dallim bëhet kur flitet për timarlinjtë. Shpeshherë shënohet edhe timarliu i mëposhtëm kur pohohet sulltani. Kështu, kur flitet për sulltan Mehmetin e I thuhet padishahu i ndjerë, ndërsa kur flitet për sulltan Muratin e II, thuhet padishahu ynë. $^{2}$

Ndryshime të rëndësishme në jetën politike ushtarake do të ndodhnin në Shqipërinë e Mesme, pas kryengritjes së Skënderbeut në vitin 1443 dhe krijimit të një fronti luftimesh mes tij dhe forcave osmane. Shqipëria e Jugut mbeti e paprekur nga ky konflikt. Përpjekja e vetme e koalicionit të ushtrisë së Skënderbeut dhe trupave napolitane për rrethimin e Beratit, si hap i parë i largimit të sundimit osman nga ajo trevë, u shuan që në fillim pas disfatës së trupave të koalicionit të kapur në befasi nga sulmi i kavalerisë osmane që drejtohej nga Ali Evrenos bej.

\section{Regjistri i 1467}

Regjistri tahrir i vitit 1467, është regjistër i detajuar (mufasal) dhe përfshin trevat e Dibrës, Rekës, Matit, Krujës dhe Çermenikës (Çermeniçe). Ai gjendet në Arkivin Osman të Stambollit në fondin MAD (regjistra të ardhur nga Ministria e Financës) nën numrin 508.

Regjistri ka qenë i njohur për historianët shqiptarë. Një përkthim i tij gjendet në bibliotekën e Institutit të Historisë së Tiranës. Një pjesë e regjistrit u botua si pjesë e botimit të titulluar Lufta shqiptaro-turke në shekullin

1 Arvanid, 89-93

2 Arvanid defteri, 89-94. 
e XV: Burime osmane. ${ }^{1}$ Interesant është fakti se në këtë botim nuk është përfshirë një pjesë e regjistrit, më saktë fletët 1-6 dhe 26-145, ku gjenden të dhëna interesante, të ndryshme si për një timar që zotërohej në kohën e Skënderbeut, ${ }^{2}$ si dhe identifikohen personat që patën kapur bashkëluftëtarët e rëndësishëm të Skënderbeut, Moisi Golemin dhe Muzakën e Angjelinës, në konfrontimin e fundit luftarak, të cilët më pas u pajisën me timare brenda sanxhakut. ${ }^{3}$

Regjistri është hartuar menjëherë pas fushatës së sulltan Mehmetit të II në Shqipërinë e Mesme, gjatë së cilës u ndërtua qyteti i Elbasanit, u rrethuan kalaja e Durrësit dhe e Krujës dhe mbi të gjitha, me sa hedh dritë regjistri osman, u bë një krehje e trevës duke u rivendosur sistemi i timareve. Ndonëse regjistri nuk shpreh qartë, mund të pretendohet se regjistri i Dibrës, Rekës, Dullgobërdës, Matit, Krujës dhe Çermenikës është hartuar mbi hapësirën ku vepronte Skënderbeu, duke përcaktuar kështu në mënyrë të tërthortë hapësirën ku sundonte ai.

Çermenika (në formën Çermeniça) nuk figuronte në regjistrin e vitit 1431 (835 hixhri) të Arvanidit. Kjo tregon se kjo njësi administrative është formuar gjatë fushatës së sulltanit në Shqipërinë e Mesme, ${ }^{4}$ ashtu siç u themelua edhe kalaja e Elbasanit.

Në regjistër identifikohet komandanti (ket'hyda) i ushtarëve të kalasë së Elbasanit në vitin 1468, Bahadiri, i cili ka një timar në nahijen e Çermenikës. ${ }^{5}$

\section{Regjistri i vitit 1530 i Rumelisë}

Regjistri është përmbledhës (ixhmal), për gjithë Rumelinë, megjithëse mungojnë pjesë për sanxhaqe të ndryshme. Ai është regjistruar në fondin DFE.TD nën numrin 367. Në këtë regjistër nuk përfshihen emrat e banorëve, as shpërndarja në produkte e të ardhurave të çdo fshati, siç ndodh në regjistrat e detajuar, por jepen të dhëna pëmbledhëse mbi njësitë

1 Selami Pulaha, Lufta shqiptaro-turke në shekullin e XV: Burime osmane, Tiranë 1968, f. 326-374.

2 Defteri i Dibrës, BOA, MAD 508, f. 54. Kur flitet për fshatin Doljan në kazanë e Koxhaxhikut shkruhet se në kohën e Skënderbeut atë e shfrytëzonte Jovan Popoviqi, ndërsa me shkresën e Haxhi beut, regjistruar në Stamboll ky fshat i jepet si timar vojnukëve Gjurko Teodorit me vëllezër dhe Nikolla Preçës, që shërbejnë me radhë në ushtri.

3 Defteri i Dibrës, BOA, MAD 508, f. 40 dhe 127.

4 Të dhëna për këtë vilajet gjenden te fletët 6, 98 dhe 124-141 të defterit të Dibrës.

5 Defteri i Dibrës, BOA, MAD 508, 136. 


\section{AlBanon}

Revistë kulturore

financiare, të ardhurat e tyre si dhe emrat e administratës ushtarako-ligjorefinanciare osmane në trevë.

Regjistri jep një tablo të rëndësishme të sanxhaqeve të ndryshme në Rumeli në vitin 1530 .

Sanxhaku i vilajetit të Elbasanit, kishte 250 fshatra (71 në kazanë e Elbasanit), 30 lagje (16 në qytetin e Elbasanit), 526 vatra myslimane (213 në kazanë e Elbasanit), 2 beqarë myslimanë, 8916 vatra të krishtera (2444 në kazanë e Elbasanit), 493 beqarë (192 në kazanë e Elbasanit), 20 trualishte (mezra, 6 prej tyre në kazanë e Elbasanit), 98 mullinj.

Qyteti i Elbasanit me të ardhurat e tij ishte llogari (has) e sanxhakbeut. Në qytet, përveç ushtarëve kishte edhe një bashkësi myslimane. Në regjistrin e vitit 1530 të dhënat e tyre jepen sipas ndarjes financiare klasike osmane: vatra, beqarë dhe të veja. Të dhënat për lagjet e qytetit të Elbasanit në vitin 1530 jepen më poshtë:

\begin{tabular}{|l|l|l|c|c|c|}
\hline Lagjet myslimane & Vatra & Lagjet e krishtera & Vatra & Beqar & E ve \\
\hline Dahil-i kala (brenda kalasë) & $100^{1}$ & Kostur & 4 & 1 & 2 \\
\hline Kosar & 8 & Narta & 8 & 3 & 0 \\
\hline Hekurpunues & 4 & Janina & 19 & 6 & 1 \\
\hline & & Ohri & 10 & 0 & 2 \\
\hline & & Vlora & 3 & 0 & 0 \\
\hline & & Shkup & 7 & 1 & 0 \\
\hline & & Sofje & 3 & 1 & 0 \\
\hline & & Serez & 9 & 3 & 0 \\
\hline & & Dhimo nallbani & 10 & 0 & 0 \\
\hline & & Okiç & 24 & 3 & 0 \\
\hline & & Cvetko & 22 & 2 & 0 \\
\hline & & Jelena & 27 & 3 & 0 \\
\hline & & Jorgo Penço & 24 & 1 & 0 \\
\hline
\end{tabular}

Të krishterët e qytetit ndaheshin në dy grupe: ata që ishin sjellë si syrgjyn që në kohën e sundimit të sulltan Mehmetit të II, pasi u ndërtua kalaja e Elbasanit dhe ata që ishin vendosur me dëshirën e tyre në qytet. Të parët ishin përjashtuar nga të gjitha taksat, përveç haraçit që ia paguanin sanxhakbeut të Elbasanit, por që më vonë, me ferman të sulltanit ishin përjashtuar edhe nga kjo taksë. Ata kryenin shërbime në kala, për nevojat që

1 Pranë kalasë (der nefsi kala) 45 vatra, ata që jetonin brenda kalasë (biruni kala), 55 vatra. 
kishte ajo (meremetime, pastrimi i hendeqeve përreth kalasë, mbarëvajtjen e urave të portave).

Në vitin 1530, qyteti i Elbasanit kishte një popullsi civile me 282 vatra (1410 persona), 24 beqarë, 5 vejusha, një total 1444 banorësh. Të ardhurat financiare që ai i jepte sanxhakbeut ishin 44’208 akça (aspra).

Në vitin 1530, forcat ushtarake të Elbasanit formoheshin nga kompania e mbrojtësve (mystahfiz) të kalasë së Elbasanit që përbëhej nga një 1 dizdar (kastelan), 1 ket'hyda, 1 hatip, 1 imam, 2 myezinë, 1 xhebexhi (kujdestari i armatimeve), 2 topçinj dhe 89 ushtarë. Të ardhurat që paguheshin si rroga ndaj tyre kapnin vlerën vjetore 106'809 aspra (akça) dhe mblidheshin nga 42 mullinj dhe 31 fshatra, ku banonin 62 vatra myslimane, 827 vatra të krishtera, 34 beqarë, 4 vejusha.

Sanxhakbeu gëzonte edhe të ardhurat vjetore 690 akça që mblidheshin nga 24 mullinjtë në kaza.

Përveç qytetit të Elbasanit, si has i sanxhakbeut të Elbasanit ishin edhe fshatra që vareshin nga kazaja e Elbasanit si: Mollagjeshi, 45 vatra, 2 beqarë, të ardhura 6160 akça; Muris, 27 vatra të krishtera, 25 vatra myslimane, 2 mullinj, të ardhura 3140 akça; Bishqem, 83 vatra, 5 beqarë, 4 mullinj, të ardhura 6726 akça; Shpati, 21 vatra, 2 beqarë, të ardhura 3352 akça; Todorjan, 39 vatra, 4 beqarë, 2 mullinj, të ardhura 3996 akça; Shelcan, 11 vatra myslimane, 2 beqarë myslimanë, 46 vatra të krishterë, 8 beqarë, 1 mulli, të ardhura 5174 akça.

Në total llogaria (hasi) e sanxhakbeut përbëhej nga 1 qytet, 13 lagje, 6 fshatra, 135 vatra myslimane, 2 beqarë myslimanë, 435 vatra të krishtera, 45 beqarë, 5 vejusha, 33 mullinj, taksat e të cilave shkonin në total 72'761 akça.

Zaimët, pra timarlinjtë që zotëronin zeamete, në total kishin një buxhet prej 71'551 akçash, që mblidheshin nga 24 fshatra dhe 6 mezra, ku banonin 14 banesa myslimane, 755 banesa të krishtera, 111 beqarë, 7 vejusha dhe 21 mullinj.

Në regjistrin përmbledhës të vitit 1530 gjendet edhe lista e municioneve që kishte kalaja e Elbasanit ku mes të tjerash në depon e armatimeve në gjendje ruheshin edhe 280 dyfekë, 160 topa të vegjël, 55 topa për rrahje muri, 30'000 shigjeta, 19 arka me gozhda të mëdha, 30 varré, 10'600 fishekë dyfekësh, një sasi lëkure, një sasi rrëshire, 5 qyski etj.

Fshati Bradashesh me akt pronësimi (mylkname) të sulltan Bajazitit të II i qe caktuar si pronë private (mylk) të ndjerit Sinan Jusuf pashës, ish-sanxhakbeut 


\section{AlBanon}

Revistë kulturore

të Elbasanit, ish-bejlerbeut të Rumelisë dhe ish-admiralit (kapedani i detit) të flotës osmane, me origjinë nga familja Borovinic e Bosnjës, ${ }^{1}$ me të ardhura 10'679 akça, ku banonin 98 vatra. Në regjistër janë edhe emrat e të afërmve të ish -anxhakbeut, të cilët janë Golemi, Mara, bijtë e Golemit dhe Pjetri Golemi, që ishin nipat nga motra dhe bijtë e hallës së sanxhakbeut të ndjerë.

Timaret e ushtarëve të kalasë së Elbasanit, kishin të ardhura në shumën 16 '050 akça, që mblidheshin nga 8 mullinj dhe 8 fshatra, ku banonin 115 vatra, 7 beqarë.

Brenda kazasë së Elbasanit gjendeshin përveç kalasë së Elbasanit edhe kalatë: e Dronikut; 1 kastelan (dizdar), 1 ket'hyda, 1 imam, 13 topçinj, 39 mbrojtës kalaje dhe një kompani azepësh me 1 aga dhe 49 ushtarë, kalaja e Bashtovës; me një 1 dizdar, 1 ket'hyda, 4 topçinj.

Administrata ushtarake osmane e sanxhakut të Elbasanit përbëhej nga 1 sanxhakbej, 3 kadinj, 2 zaim, 109 spahinj, 4 dizdarë.

Tek objektet e kultit në sanxhak gjendeshin 3 xhami, 9 mesxhide, 1 teqe, 2 medrese.

Të ardhurat totale të sanxhakut të Elbasanit ishin 1'260'264 (293'651 prej të cilave në Elbasan), nga të cilat 346'882 akça të sulltanit, 200'000 akça të sanxhakbeut, 432'087 akça për zaimët dhe timarlinjtë dhe 280'616 akça për mystahfizët e kalasë.

Të ardhurat e disa fshatrave shkonin për rrogat e administratës fetare, kështu fshati Shingjin, timar dhe hise e myezinit të kalasë së Elbasanit; fshati Luga, timar dhe hise e myezinit ( 1 vatër myslimane dhe 6 vatra të krishtera); $B z r k^{2}$ i madh, timar hatipi xhamisë së kullës së Elbasanit (20 vatra të krishtera); Petresh, timar i imamit, myezinit dhe administratorit (kajum) të xhamisë së Elbasanit (4 vatra myslimane, 40 vatra të krishtera, 3 beqarë të krishterë).

\section{Regjistri i detajuar (mufasal) i vitit 1568}

Defteri i detajuar tahrir i vitit 1568 është hartuar në kohën e sundimit të sulltan Selimit të II, nga Mehmed, biri i Mustafait, i njohur si Ibn Dulbendi, si mbikqyrës regjistrimi dhe nga Mehmedi, biri i Jakupit, si sekretar.

1 Michael Kiel, zëri Elbasan (Illbasan), Enciklopedia Islame (DiA), vëllimi XXII, fq. 79-81, İstanbul 2000.

2 Fshat i paidentifikuar, shënuar sipas regjistrit Osman. 
Me datë 23 zilhixhe 975 H (19 qershor 1568) i është parashtruar fronit sulltanor, ndërsa me datë sheval 977 (mars 1570) i është dorëzuar divanit perandorak (këshilli i shtetit).

Në 1568, në kohën e sulltan Selimit të II, plot njëqind vjet nga organizimi administrativ i vitit 1468, sanxhaku i Elbasanit formohej nga katër kaza: Elbasani, Çermenika, Shpati dhe Durrësi. Tre kazatë e para kishin nën varësitë e tyre në total 191 fshatra, përkatësisht, Çermenika 23 fshatra, Shpati 101, Elbasani 67 fshatra.

Qyteti i Elbasanit ishte has i sanxhakbeut. Të dhënat për lagjet dhe popullsinë e tyre në vitin 1568 janë si më poshtë:

\begin{tabular}{|l|c|l|c|}
\hline \multicolumn{1}{|c|}{ Lagjet myslimane } & Vatra & \multicolumn{1}{c|}{ Lagjet e krishtera } & Vatra \\
\hline Brenda kalasë & 25 & Kostur & 5 \\
\hline Çavushlli & 89 & Janina & 10 \\
\hline Haznedar & 31 & Ohri & 2 \\
\hline Debaghane & 40 & Vlora & 4 \\
\hline Myslimanë të rinj & 8 & Shkup & 2 \\
\hline Dylgjer & 18 & Sofje & 3 \\
\hline Bozaxhijas & 4 & Okiç & 10 \\
\hline Dunxhijas & 20 & Gjuriça & 13 \\
\hline Hajmegan & 88 & Vaska & 8 \\
\hline Koptijan & 5 & Kakruk & 1 \\
\hline Hekurpunues & 4 & Stefo & 13 \\
\hline
\end{tabular}

Fshati Bradashesh, vazhdonte ashtu si në vitin 1530, të kishte statusin e fshatit mylk, pra pronë private dhe i takonte pasardhësve të ish sanxhakbeut të Elbasanit, Sinan pashës.

Në regjistër gjendet edhe Rregullorja e sanxhakut të Elbasanit (Kanuname e Elbasanit). Përkthimi shqip i saj është i botuar. ${ }^{1}$

Në dallim me regjistrin përmbledhës të Rumelisë së vitit 1530, në këtë regjistër nuk ka të dhëna përmbledhëse, madje as në fund të të dhënave të çdo kazaje, gjë e rrallë në këto lloj regjistrash. Ashtu siç ndodh në regjistrat e detajuar, jepen emrat e kryetarëve të familjeve dhe emrat e beqarëve.

Disa fshatra kishin statusin derbend. Ato ishin Murrisi, Garunja, Polisi, Qirulesh, Fëndëklu (Findıklu = fshati me gështenja).

1 Burime të zgjedhura për historinë e Shqipërisë, Vëllimi III, Tiranë 1962. 


\section{Albanon}

Revistë kulturore

Fakti që këto fshatra ishin derbend, tregon se nëpër ato kalonte rruga e udhëtarëve, prandaj kishin rëndësi strategjike ushtarake, tregtare dhe publike (pasi sigurohej kalimi i sigurtë). Në mesin e tyre, më interesanti paraqitet fshati derbend i Buzurshekut. Buzursheku është identifikuar me Buzeshkun nga një pjesë e historianëve shqiptarë, ndërsa regjistri osman e lokalizon atë në fshatin Polis. Gjatë fushatës osmane të vitit 1466 kjo pikë ka qenë një ndër pikat strategjike ku Skënderbeu, ngriti një pritë për të penguar marshimin e ushtrisë osmane, fakt për të cilin njofton edhe kronikanti osman Tursun bej, sipas të cilit në këtë pikë u zhvillua edhe një përplasje e ashpër mes trupave osmane dhe atyre të Skënderbeut. ${ }^{1}$

Në regjistër janë shënuar edhe fshatrat që njiheshin në atë kohë me dy emra (nam-1 diger / allias). Ato janë Kotormani i njohur edhe si Konjar Manes, në kazanë e Çermenikës, Shënepremte e njohur edhe si Fushtanis, në kazanë e Shpatit, çifligu i Mehmed Çelebiut, i njohur si Proshka, në kazanë e Shpatit, Buzurshek i njohur si Polis, në kazanë e Shpatit.

Emigrimi i brendshëm ka qenë një ndër fenomenet më të përhapura brenda Perandorisë Osmane. Grupe banorësh shpërnguleshin nga vendbanimet e tyre me dëshirë, në kërkim të mjediseve dhe vendeve më komode dhe më frytdhënëse për veprimtarinë e tyre bujqësore. Kjo lëvizje e popullsisë nuk pranohej nga administrata financiare, pasi me vendbanimet ishin të lidhura edhe detyrimet financiare. Vetëm për arsye sigurie, popullimi, interesa të shtetit apo arsye të tjera, sulltani mund të jepte fermanin me të cilin konfirmonte vendbanimet e reja. Një tjetër leje jepej automatikisht kur banorët e rinj vendoseshin në vendbanimet e reja dhe adminstrata ushtarako-financiare nuk kishte arritur t’i zbulonte për një periudhë më shumë se njëzet vjet. Për të nxitur gjetjen dhe regjistrimin e fshatrave të paregjistruara, osmanët ndiqnin politikën e motivimit: fshati dhe të ardhurat e tij i caktoheshin automatikisht si timar personit që i zbulonte ato. Në regjistrin e tahririt mufasal të vitit 1568, gjenden edhe gjurmë të emigrimit të brendshëm të popullsisë nga njëri fshat në fshatra të tjera ose në qytet. Kështu përveç lagjeve të formuara me urdhër të sulltan Mehmetit të II, pas themelimit të qytetit të Elbasanit, kemi edhe lagje të formuara me persona që kishin ardhur me dëshirën e tyre dhe lejen e administratës osmane dhe qenë vendosur në Elbasan, të cilat kishin marrë emrat e të parit që kishte drejtuar familjet për t’u vendosur në Elbasan.

1 Tursun bej, Tarih-i Ebu'l-Fet'h, Mertol Tulum, İstanbul 1977, 144 
Lagja e Bozaxhinjve, ishte formuar me individë që kishin ardhur nga fshatrat përreth Elbasanit.

Në lidhje me lëvizjen e popullsisë (imigrimi), regjistri ka shënuar këto raste: Bishqem (f. 18-20): 1 i ardhur nga fshatri i kazasë së Elbasanit; Pajnika (f. 44-45): 3 të ardhur nga Ollma, Mamli, Lleshani; Lukani (f. 46): 1 i ardhur nga Shëngjini; Preça e poshtme (f. 47): 2 të ardhur nga Shënmartini dhe Dragostunja; Godolesh (f. 49): 7 të ardhur nga Kushova.

Më poshtë gjendet edhe një tabelë përmbledhëse në lidhje me popullsinë myslimane dhe jomyslimane në fshatrat e kazasë së Elbasanit në vitin 1568:

\begin{tabular}{|l|l|r|r|r|r|}
\hline $\begin{array}{l}\text { Kazaja } \\
\text { Elbasan }\end{array}$ & Fshati & $\begin{array}{l}\text { Vatra } \\
\text { mysliman }\end{array}$ & $\begin{array}{l}\text { Beqar } \\
\text { mysliman }\end{array}$ & $\begin{array}{l}\text { Vatra të } \\
\text { krishtera }\end{array}$ & $\begin{array}{l}\text { Beqar të } \\
\text { krishterë }\end{array}$ \\
\hline & Pajun & 18 & 9 & 0 & 0 \\
\hline & Konijas & 30 & 9 & 0 & 0 \\
\hline & Konijas tjetër & 0 & 0 & 8 & 2 \\
\hline & Bishqem & 57 & 23 & 181 & 21 \\
\hline & Murrs & 181 & 16 & 3 & 0 \\
\hline & Cëruja & 0 & 0 & 39 & 13 \\
\hline & Luga & 8 & 3 & 7 & 2 \\
\hline & Lepur & 8 & 0 & 34 & 0 \\
\hline & Bistra & 0 & 0 & 4 & 1 \\
\hline & Kora & 3 & 1 & 59 & 19 \\
\hline & Shëngjergj & 0 & 0 & 11 & 4 \\
\hline & Zabzun & 3 & 0 & 6 & 1 \\
\hline & Ranesh & 2 & 3 & 2 & 1 \\
\hline & Malagjesh & 4 & 1 & 79 & 30 \\
\hline & Kokonja & 47 & 24 & 34 & 14 \\
\hline & Kllojka & 2 & 1 & 31 & 6 \\
\hline & Todharin & 13 & 5 & 41 & 10 \\
\hline & Griqan & 1 & 0 & 103 & 28 \\
\hline & Mnkol & 0 & 0 & 23 & 9 \\
\hline & Shargjen & 5 & 2 & 14 & 4 \\
\hline & Kovas & 8 & 2 & 9 & 2 \\
\hline & Shpat & 59 & 21 & 0 & 0 \\
\hline & Pajova & 45 & 16 & 16 & 6 \\
\hline & Bllajça & 26 & 9 & 7 & 3 \\
\hline & Vidhas & 26 & 10 & 0 & 0 \\
\hline & Matra & 8 & 1 & 3 & 2 \\
\hline & Garunja & 63 & 17 & 23 & 3 \\
\hline & Cacbeza & 50 & 9 & 9 & 5 \\
\hline & & & & & \\
\hline
\end{tabular}




\begin{tabular}{|c|c|c|c|c|c|}
\hline $\begin{array}{l}\text { Kazaja } \\
\text { Elbasan }\end{array}$ & Fshati & $\begin{array}{l}\text { Vatra } \\
\text { mysliman }\end{array}$ & $\begin{array}{l}\text { Beqar } \\
\text { mysliman }\end{array}$ & $\begin{array}{l}\text { Vatra të } \\
\text { krishtera }\end{array}$ & $\begin{array}{l}\text { Beqar të } \\
\text { krishterë }\end{array}$ \\
\hline & Shalës & 2 & 0 & 12 & 4 \\
\hline & Manes & 3 & 0 & 32 & 10 \\
\hline & Balza & 1 & 0 & 34 & 13 \\
\hline & Terbaç & 16 & 2 & 7 & 2 \\
\hline & Rojimal & 10 & 1 & 5 & 3 \\
\hline & Bixulla & 4 & 0 & 53 & 18 \\
\hline & Branesh & 4 & 1 & 3 & 1 \\
\hline & Maroshin & 0 & 0 & 8 & 3 \\
\hline & $\begin{array}{l}\text { Preça } \\
\text { sipërme }\end{array}$ & 3 & 1 & 17 & 4 \\
\hline & Pajnika & 24 & 9 & 18 & 5 \\
\hline & Karmash & 0 & 0 & 5 & 2 \\
\hline & Shingjin & 8 & 2 & 39 & 13 \\
\hline & Letan & 18 & 4 & 12 & 2 \\
\hline & Gjonm & 0 & 0 & 3 & 0 \\
\hline & $\begin{array}{l}\text { Preça e } \\
\text { poshtme }\end{array}$ & 0 & 0 & 38 & 11 \\
\hline & Veskanj & 16 & 3 & 8 & 2 \\
\hline & Godolesh & 0 & 0 & 49 & 12 \\
\hline & Byzrk i vogël & 0 & 0 & 4 & 0 \\
\hline & Petrash & 13 & 5 & 28 & 8 \\
\hline & Jatesh & 13 & 8 & 50 & 8 \\
\hline & Ollma & 15 & 4 & 41 & 8 \\
\hline & Shtëmaj & 17 & 6 & 18 & 10 \\
\hline & Gracen & 31 & 11 & 3 & 1 \\
\hline & Gurazez & 0 & 0 & 30 & 9 \\
\hline & Rrila & 9 & 2 & 8 & 2 \\
\hline & Byzrk i madh & 2 & 1 & 8 & 2 \\
\hline & Kozani & 27 & 6 & 9 & 3 \\
\hline & Shingjon & 15 & 5 & 13 & 6 \\
\hline & Pallankaniça & 24 & 5 & 19 & 9 \\
\hline & Karroq & 1 & 0 & 8 & 2 \\
\hline & Ursula & 3 & 1 & 0 & 0 \\
\hline & Bizhuta & 59 & 24 & 11 & 3 \\
\hline & Bradashesh & 7 & 3 & 114 & 30 \\
\hline & Total & 1'012 & 283 & 1'453 & 392 \\
\hline
\end{tabular}

